\title{
A DSM Comparative Study of PTSD Incidence in Indonesia
}

\author{
Louis L Downs \\ University of California Davis \\ School of Medicine, Department of Public Healthcare Policy
}

Ahmad Ali Rahmadian

Al-Biruni Cerdas Mulia Islamic School

Elvi Noviawati

Al-Biruni Cerdas Mulia Islamic School

Goolrukh Vakil

Sofia University

\section{Suswati Hendriani}

Sekolah Tinggi Agama Islam Negeri, (STAIN University), Batusangkar

Pengiran Seti Aminah Binti Pengiran Othman

Universiti Brunei Darussalam

\section{Masril Masril}

Sekolah Tinggi Agama Islam Negeri, (STAIN University), Batusangkar

Pengiran Seti Aminah Binti Pengiran Othman

Universiti Brunei Darussalam

\author{
Diane Kim \\ Peace Corps, Cameroon
}

\begin{abstract}
A research project measured PTSD incidence in disaster-prone zones of Indonesia, Java six and Sumatra three years post-disaster. The Downs Posttraumatic Stress Scale, a new instrument with high reliability for children and adults $(\alpha=.94)$, measuring incidence of 28 identified PTSD symptoms was developed. Analysis revealed unusually high continuing incidence of PTSD. The results of analysis also compared PTSD incidence between the DSM IV-TR (24.14\%) with the DSM 5 (20.1\%), a significant decrease in diagnosability.
\end{abstract}

Keywords: Posttraumatic Stress, disaster, DSM 5, diagnosability

\section{INTRODUCTION}

Southeast Asia is highly vulnerable to natural disasters (Ito, Setoya, \& Suzuki, 2012; Kokai, Fujii, Shinfuku, \& Edwards, 2004; Udomratn, 2008). Posttraumatic Stress Disorder (PTSD) has been reported as a common post-disaster psychological reaction to the calamities that befall the area (Chung, Werrett, Farmer, Easthope \& Chung, 2000). At the same time, the cultural climate of this region stigmatizes mental illness, which has been linked to underreporting of psychological disorders, and to a regular occurrence of PTSD (Ito, Setoya, \& Suzuki, 2012; Kokai, Fujii, Shinfuku, \& Edwards, 2004). 
At the same time, in much of Southeast Asia, interventions have followed only the first two steps of Rao's (2006) four stages of intervention: the rescue phase (0-2 weeks post-disaster), the relief phase (2-6 months post-disaster), the rehabilitation phase (1-2 years post-disaster), and the rebuilding phase (many years post-disaster). Post-disaster interventions in Southeast Asia necessarily have focused on immediate medical aid and infrastructure repair with attention to mental health treatment being secondary (Leitmann, 2007). Further, although attention is now being drawn to psychosocial and mental health post-trauma needs and in formulating a pre-trauma mental health system as essential to prepare for future disasters (Panyayong \& Pengjuntr, 2006; Satapathy \& Subhasis, 2009), actual measures toward construction of systems of care is still in its infancy.

Schnurr (2010) stated that, because most of the ten worst natural disasters of the past century have occurred in Asia, there is a need for more extensive research on PTSD in developing Asian countries. Although professionals in the region regularly record symptoms of posttraumatic stress, PTSD was unknown to Asians prior to the 2004 Indian Ocean tsunami and thus not treated (Udomratn, 2008). Further, studies of PTSD in South East Asia that do exist, vary methodologically. As late as 2012, studies of PTSD were deficient in some regions such as Malaysia and Indonesia (Ghazali, Yaman, \& Ahmad, 2012).

US Department of Veterans Affairs, National Center for PTSD (2013) stated that whereas, disaster research reveals many common effects between different disasters, each disaster is unique. The Center asserted that, besides the natural differences such as aftershocks, factors intrinsic to a country such as infrastructure and cultural beliefs also affect the outcome of the physical and emotional wellbeing of survivors.

A clinical trial showed that acceptance of mental health counseling in the wake of disaster resulted in reduced hospital admissions and shorter hospitalization (Ito, Seoya, \& Suzuki, 2012). Further, early identification of high-risk individuals and early interventions to reduced onset of PTSD (Bryant, 2006; Ghodse \& Galea, 2006). Adequate research and epidemiologic studies on the nature of PTSD and the prevalence of post-disaster PTSD in Southeast Asia would lend credence to ongoing mental health interventions and to formulation of preparations for future disasters.

\section{Posttraumatic Stress Symptoms and Diagnosis}

Posttraumatic stress disorder has long been known to be a typical psychological outcome of a period of traumatic situations that include such events as war (Ehntholt \& Yule, 2006), physical and sexual assault (Fairbrother \& Rachman, 2006), severely repressive governments (Brown, 2006), and natural or human caused disasters (Satapathy \& Walla, 2006; See, 2005). According to the International Classification of Diseases 10 (World Health Organization, 1994), the more universally accepted psychiatric taxonomical system, PTSD symptoms fall into three clusters. These clusters included; 1 ) recurrent and intrusive, distressing recollections of the traumatic event, 2) persistent avoidance of stimuli related to the aftermath of the trauma, and 3) persistent hyperarousal. The soon to be published ICD 11 has explored a more multifaceted diagnosis of PTSD. Research that studied 9-11 survivors has revealed that those who met the criteria for a three-cluster diagnosis of PTSD had singularly experienced the catastrophe of the attack on the Twin Towers. Other 9-11 survivors who met the above criteria but also presented with added symptoms, including interpersonal problems as well as belief in ongoing threat, invariably reported a history of multiple traumatic experiences (Cloitre, Garvert, Brewin, Bryant \& Maercker, 2013). 
The previous edition of the Diagnostic and Statistical Manual, edition IV-TR (American Psychiatric Association, 2000), agreed with the ICD 10 regarding three symptom clusters but identified more specific symptoms inside of these diagnostic clusters. The newer edition of the DSM, the Diagnostic and Statistical Manual 5 (American Psychiatric Association, 2013) reorganized the symptom clusters by adding a new cluster, negative alterations in cognition and mood, and moving many symptoms from the clusters, avoidant behaviors, invasive symptoms and hyperarousal, to the new cluster. Derealization and depersonalization were entirely removed as diagnostic criteria and became added features for identification upon diagnosis.

\section{Diagnostic Disagreements and Similarities Between Editions}

Although the DSM 5 was decisive regarding its new taxonomical schema, there is growing disagreement regarding diagnostic criteria for PTSD both within the ranks of therapeutic professionals and internationally.

There is not only increasing disagreement between the $I C D$ and the $D S M$ but also significant discrepancy between the earlier DSM IV-TR and the recently published DSM 5 without published research to support changes. These incongruences include what symptom clusters define PTSD, how the clusters are organized, and how many criteria are required in each cluster to qualify for diagnosis, (American Psychiatric Association, 2013; American Psychiatric Association, 2000; US Department of Veterans Affairs, 2013). There is, however, general agreement on the description of what symptoms occur for those suffering from PTSD. Intrusive experiences that occur after the traumatic event include recurring memories and thoughts about the event, distressing dreams, acting or feeling as if the event is recurring including flashbacks, hallucinations, illusions or reliving the experience - anxiety during incidents that resemble the event, or physiological reactions to cues that symbolize aspects of the event. Avoidant behaviors include efforts to avoid places, people or activities that arouse recollections, thoughts, feelings or conversations regarding the event. Hyperarousal symptoms include difficulty sleeping, irritability, angry outbursts, concentration difficulty, hypervigilance, mistrust, and an exaggerated startle response.

Even before the advent of the DSM 5 and the upcoming ICD 11, there was some disagreement between the DSM IV-TR and the ICD. These divergences between taxonomies included classification of amnesia; diminished interest in significant activities; feeling detached or estranged from others, or presenting restricted affect. The DSM IV-TR also included foreshortened future and numbing as identified symptoms.

Importantly, there is significant disagreement among psychological and medical professionals as to the accuracy or efficacy of either of the major taxonomical systems (Chafee, 2012; Frueh, Elhai, \& Acierno, 2010; Kvavilashvili, 2014; Rose, Spitzer \& McHugh, 2008). The debate over the reliability of the nosology for clinical use centers on issues of missing unclassified features or, importantly, the unmentioned cluster, interpersonal issues (Cloitre, et al., 2013; Iverson et. al, 2011; Robertson, Rushton, Bartrum, \& Ray, 2004). Discussions and research led to the development of Interpersonal Therapy for PTSD. However, the newly published DSM 5 continued without acknowledgement that interpersonal problems are related to PTSD. Conversely, the World Health Organization has finally included interpersonal symptoms in their study toward the forthcoming ICD-11, due out in 2017 (Cloitre, et al., 2013).

Having considered the differences between the diagnostic criteria of the World Health Organization's ICD and those of the American Psychiatric Association's DSM, there is an even 
more dramatic difference between the DSM-IV and the recently published DSM 5. Without straining the limitations of this research article some changes still remain critical to the discussion.

The dramatic changes in diagnostic criteria as well as in organization of these criterion symptoms from three to four symptom clusters may seem more accurate, but the question remains, what effect does adding a fourth cluster and requiring that an individual must have symptoms from every cluster to qualify for diagnosis have on incidence of the diagnosis of the disorder? This potential effect has not been tested and so becomes a critical issue for research and potentially for the efficacy of the DSM 5, clinically. Will the additional requirements to meet diagnostic threshold have an impact on the ability of survivors of traumatic experiences to qualify for treatment? To this point, the DSM 5 has been the most controversial edition of the American Psychiatric Association's five revisions of the earliest manual for diagnosis, including a significant movement within psychological circles to boycott and refuse to use the new manual altogether (Flamez, 2015; Williams \& Audet, 2015; Varley, 2015).

\section{Factors Related to Incidence of PTSD}

Several factors have been identified in various studies that appear to be predictive of or related to incidence of PTSD. Proximity to the epicenter of the disaster, post disaster financial, female gender (Briere \& Elliott, 2000; Keane, Wolfe, \& Taylor, 1987), and increased age over 40 (Norris, et al., 2002; Pyari, Kutty, \& Sarma, 2012) are considered highly predictive of PTSD severity. Preexisting mental instability (Briere \& Elliott, 2000; Ozer, Best, Lipsey, \& Weiss, 2008) and family psychopathology (Ozer, Best, Lipsey, \& Weiss, 2008; Thienkrua et al., 2006; Vijayakumar, Kannan, \& Daniel, 2006) as well as isolation (Tang, 2007) emerged as related to incidence PTSD. Further, lack of shelter, food and water (Chen et al., 2001; Dewaraja, \& Kawamura, 2006), loss of livelihood (van Griensven et al., 2006) and poor living conditions that persist after disaster (Kuwabara et al., 2008) have been shown to be related to poor overall mental health. History and number of preexisting traumas have been linked to increases in PTSD (Briere \& Elliott, 2000; Cloitre, Garvert, Brewin, Bryant, \& Maercker, 2013; Ghazali, Elkilit, Yaman, \& Ahmad, 2013; Soysa, 2013; Stratton et al., 2014; Ularntinon, et al., 2008), as were family deaths due to disaster (Kumar et al., 2007; Pyari, Kutty, \& Sarma, 2012).

Children have been identified as having unique, age-related issues with posttraumatic stress. The level of danger and sustained loss have been linked to incidence of PTSD (Thienkrua et. al, 2006), particularly among older children (Piyasil et al., 2011), who also recovered more slowly than did younger children (Iwadare et al., 2014). On the other hand, children appear to have suffered different symptoms than did adults in studies (Thienkrua et. al, 2006); children tended to exhibit more symptoms of interpersonal problems and anxiety while adults appeared to exhibit more intrusive and avoidant symptoms (Downs \& Othman, 2013).

\section{Incidence of PTSD Over Time}

A study of adult survivors of the disaster $(n=265)$ by Tang (2007) identified that $22 \%$ reported traumatic stress symptoms at two weeks and 30\% at six months. PTSD was considered the most prevalent post-disaster disorder in Thailand for in another study of adult survivors (Thavichachart et al., 2009). The study discovered that 33.6\% of 3,133 participants were diagnosed with PTSD. A follow-up study by the authors, six months later, identified that $21.6 \%$ of participants continued to be diagnosed with chronic PTSD.

Meanwhile, Kar and Bastia (2006) found that the incidence of PTSD in a study of adolescent, Thai survivors was 26.9\%. Further evidence of lingering PTSD symptoms months after the 
disaster was described in the report of a study by Piyavhatkul and colleagues (2008). The study revealed that 31 out of 94 children were diagnosed with PTSD ten months following the tsunami disaster.

In contrast to the large numbers of PTSD victims over the first several months after a disaster, a study by Piyasil and colleagues (2011) tracked the incidence of diagnosable PTSD in children over 5 year $(n=1615)$. Six weeks after the disaster the study identified 573 diagnosable cases. The number steadily dropped over 5 years to $2.7 \%$ of study participants. A study of children after a 2006 tsunami in Tamil Nadu recorded a 70\% rate of PTSD 8 months later (John, Russell, \& Russell, 2007). However, services and counseling were improved in the district, and after another tsunami survivors no longer had a fear of recurrence of tsunami and PTSD rates were significantly lower (Pyari, Kutty, \& Sarma, 2012). In Aceh, Indonesia, school-age children and adolescents living in barracks for at least 30 months post-tsunami were three times more likely to have tsunami-related fears compared to those living in villages (Du, et al., 2012).

The research carried out in disaster-prone zones of Indonesia by the authors of this manuscript intended to measure the incidence of PTSD in areas of the country that had never experienced post disaster counseling or psychotherapy, a unique endeavor. But during the preparation for the research project the APA published the DSM 5, so the research planning team decided that it should develop and instrument that could measure PTSD symptoms, whether diagnostic criterion or not, and then to treat the results in such a way as to take the opportunity to compare the DSM 5 to the DSM IV-TR to discover the potential impact of the new diagnostic threshold on diagnosability.

\section{METHODOLOGY}

There were several objectives in this study of a large Indonesian population across several disaster zones. An instrument (the Downs Posttraumatic Stress Scale) was developed that could be used with both adults and children so as to be able to make congruent comparisons across age, and that would measure not only diagnostic threshold symptoms but to be able to compare different taxonomy systems. Thus, the newly developed scale would include all 28 identified signs and symptoms of posttraumatic stress. Further, the instrument was designed to measure not just incidence but frequency and intensity of symptoms related to posttraumatic stress. Nine scholars from the United States, Indonesia, Malaysia, and Brunei met for one week to plan the research project and to refine and translate the instrument. The research group consisted of two registered psychologists, four counseling scholars, a child development expert, an educational expert, and two counseling doctoral students.

Validity was a primary concern of the nine scholars on the planning team. The Downs Posttraumatic Stress Scale (DPTSS) recorded the incidence of both diagnostic criteria symptoms as well as related symptoms regularly identified in the Diagnostic and Statistical Manual of Mental Disorders 5 (American Psychiatric Association, 2013), International Statistical Classification of Diseases and Related Health Problems, 10 ${ }^{\text {th }}$ Revision (World Health Organization, 2010), and the Diagnostic and Statistical Manual of Mental Disorders IV-TR (American Psychiatric Association, 2000), and including a comprehensive compendium of research that identified recurring symptoms in PTSD victims. Finally, the scale also recorded both the frequency and intensity of each of the 28 symptoms using an integral scales. Internal reliability proved to be high ( $\mathrm{a}=.92-.949)$ and consistent across age, culture, gender, and site (Downs, et al., 2015). 
Other objectives included to measure the incidence of Posttraumatic Stress Disorder in disaster zones which received no subsequent mental health services (a unique circumstance), as well as a comparison of diagnosed cases between the DSM IV-TR and the recently published DSM 5, and to consider relationships between frequency and intensity of the 28 identified signs and symptoms identified among PTSD victims.

One of the requirements for this study was to identify sample populations that had experienced severe natural disasters and that have neither the international support nor the infrastructure to provide mental health care following those events. Indonesia was ideal for such a study. So, a criterion study was undertaken with the sample population drawn from identified locales in West Java and West Sumatra. Both regions are tectonically active because of their location in the most active region of the Ring of Fire, specifically adjacent to the Sunda Trench (Pramono, 2014).

Research teams were formed from counseling students and faculty members of Universitas Pendidikan Indonesia in Bandung, Java, and from Sekolah Tinggi Agama Islam Negeri (STAIN University) in Batusangkar, Sumatra, to disseminate the DPTSS and to supervise groups of respondents as they recorded their responses to each item. Both teams were trained to administer the DPTS Scale during two-day sessions at each university, conducted by a Behasa Indonesia speaking member of the research planning team. All team members had been trained in crisis intervention counseling skills.

\section{Population}

The Java sites for the study, the Pangandaran beach resort areas, were suggested by the West Java Disaster Management Bureau because of the July, 2006 tsunami (BBC News, 2006) - with a death toll of 520 and 275 missing. The population of the province is the highest in density in Indonesia, with 46.3 million residents (Suwarni, 2011).

In Sumatra the residents of the two areas affected by the September, 2009 earthquake, Padang City and Padang Pariaman Regency were chosen (Antara News, 2009). A total of 1,117 deaths had been reported, 675 in Padang Pariaman Regency and 313 in Kota Padang. Seriously injured included 1,214 while less serious injuries totaled 1,688. There were 135,448 houses destroyed, with another 143,984 houses damaged but habitable, and 17 houses entombed (Kompas.com: October 15, 2009). The population of West Sumatra Province is 4,846. The population of Padang City is 833,562, and of Padang Pariaman, 391,056 909 (Warta \& BKKBN, 2011).

\section{Sample}

The research team on Java was referred to the communities of Pangandaran and Legok Jawa Cimerak and assigned to schools by the Pangandaran Bureau of Education to draw its youth sample. Teachers and staff agreed to participate, as did members of the community who had been informed of the study. The rural Sumatra sites were chosen by proximity to the ocean and by statistical reports that identified areas which had sustained the most damage and loss of life throughout the past several years of high seismic activity. Communities and schools, which agreed to participate, were included. Because Padang was the urban area that has been recently hardest hit, consultation with Wali Negari (Village heads) and Wali Korong (neighborhood community leaders) produced referrals to the most devastated communities. Schools in these communities that readily cooperated were chosen, and two community centers contacted potential participants and referred them to the research team. 


\section{RESULTS}

Sample populations were drawn from Western Sumatra and West Java $(n=1084)$. The two sites in West Java included the largest sample population $(n=370,34.1 \%)$ and $20.4 \%(n=221)$; while Western Sumatra consisted of 4 communities, which comprised in descending order of overall sample size 23.2\% $(n=251), 9.4 \%(n=102), 6.8 \%(n=74)$, and $6.1 \%(n=66)$. All participants $(n=1084)$ completed the Downs Posttraumatic Stress Scale. There was a 100\% return rate of research questionnaires by participants.

Study participants included $56.5 \%$ females $(n=612)$ and $43.2 \%$ males $(n=468)$ with 4 participants not identifying gender. The sample population in all sites was skewed toward youth, with the age range of participants from ages 8 to 89 and a median age of 15 (interquartile range=13-17). Seven participants did not identify their ages. Ethnically, participants were representative of six distinct cultures. Sundanese was the largest ethnic group comprising $48.2 \%$ of the sample population $(\mathrm{n}=522)$, all from West Java. Menangkabau, living in West Sumatra, was the second largest ethnic group, 44.6\% $(n=483)$. Other cultures comprised a small percentage of the sample, including 5.4\% Javanese $(n=58), 0.7 \%$ Malay $(n=8), 0.1 \%$ Buginese $(n=1)$, and 0.1\% mixed-race Chinese-Sundanese $(n=1)$ making up the rest of the sample. Except for 2 Malay, all minority populations lived in West Java.

Participants were asked what their religious preference was. Of the 1084 sample population all reported themselves to be Muslim except 3, who identified as being Christian. Participants were asked their marital status before and after experiencing the identified primary traumatic event. Predisaster marital status was reported as $85.7 \%$ single ( $n=929), 12.5 \%$ married $(\mathrm{n}=135), 1.5 \%$ widowed $(\mathrm{n}=16), 0.2 \%$ divorced $(\mathrm{n}=2)$, and $0.1 \%$ living as married $(\mathrm{n}=1)$. Postdisaster marital status was reported as $84.4 \%$ single $(n=915), 12.7 \%$ married $(n=138), 2.1 \%$ widowed $(n=23), 0.5 \%$ divorced $(n=5)$, and $0.2 \%$ living as married $(n=2) . \quad$ A Chi Square reported a significant difference between pre and post disaster marital status $\left(x^{2}{ }_{16}=1998.33\right.$, $p<.000, n=1083$ ) with post-disaster marriage and widowing as the significant differences.

Because the intention of this study was to sample disaster-prone geographical areas, all participants had experienced some sort of traumatic incident, some related to living in coastal Ring of Fire locales and others related to living in rural locations with intrinsic environmental risks (earthquakes or volcanoes) or dangerous roads. Participants were asked to identify all experienced catastrophes but to also name the single event that was the most traumatic. Although many of the subjects reported that they had experienced multiple disasters, the study reduced these data to the, respondent-reported, most traumatic experience. There were 34 separate types of traumatic incidents identified. The most numerous reported significant incidents were tsunami, 42.1\% $(n=456)$, followed by earthquake, 40.1\% $(n=435)$. Vehicular accidents accounted for $5.2 \%(n=56)$, while the only other multiple reports of most significant event included near drowning $(1.9 \%, \mathrm{n}=21)$ and animal attacks $(1.2 \%, \mathrm{n}=13)$.

A Chronbach's alpha was performed on the database to assess reliability of the DPTS Scale (Santos, 1999). Of the 1084 returned questionnaires, 18 were excluded from frequency and intensity of symptoms analysis because they did not report these data, and so were only partially informative. A Chronbach's alpha revealed internal consistency $(a=.94)$. Further reliability testing was performed to compare the reliability of the scrambled to the symptomclustered versions of the Scale. Further testing confirmed consistently high reliability across cultures - Menangkabau ( $a=.949)$, Javanese $(a=.949)$, and Sundanese ( $a=.92)$. 


\section{RESULTS OF COMPARATIVE ANALYSIS OF DIAGNOSTIC THRESHOLD BETWEEN THE DSM} 5 AND DSM IV-TR

The research team wished to establish incidence of PTSD in areas hit by disasters using both the measures of the DSM 5 and the DSM IV-TR and then later to compare the results of both criteria. The initial intention was to discover any differences that might have occurred between this sample population and those from other studies who had received counseling. However, since the DSM 5 was newly published, a secondary hypothesis was formed, that there would be no significant difference in sensitivity to PTSD diagnosis between the two taxonomical structures.

First, using the DSM 5 diagnostic criteria, the overall incidence of PTSD across the sample populations in Sumatra and West Java $(n=1084)$ was $20.9 \%, s d=.407(n=227)$. West Java participants reported an overall rate of $19.63 \%, \mathrm{sd}=.398(\mathrm{n}=116)$ six years after the earthquake. Sumatra participants reported a rate of $22.52 \%, .418(n=111)$ three years after the latest earthquake, again not significantly different between Java and Sumatra, even though there was a three year hiatus between site-bound catastrophes. Comparisons of the 6 specific sites revealed that differences in diagnostic rates were not significant according to DSM 5 criteria, although the rates ranged from $29 \%$ and $26 \%$ in the two most remote Sumatran sites to $12 \%$ in Padang City, and from $22 \%$ in the most affected area of West Java to $18 \%$ in the other site.

A preliminary test was performed using a logistic regression to determine if any of the various factors might be related to diagnosability. Only gender appeared to be practically significant so a Chi Square was performed and revealed a significant difference between diagnosable rates by gender, $X^{2}(1, \mathrm{n}=1080)=7.329, p=.007$. Female participants reported a higher rate of PTSD $(23.9 \%)$ than did male participants $(17.1 \%)$.

Next, using the DSM IV-TR diagnostic criteria, the data were reanalyzed. The overall incidence of PTSD across the sample populations in Sumatra and West Java $(n=1084)$ was $24.14 \%$, $\mathrm{sd}=.428(n=261)$. West Java participants reported an overall rate of $22.28 \%, \mathrm{sd}=.416(\mathrm{n}=131)$ six years after the earthquake. Sumatra participants reported a rate of $26.37 \%$, sd=.44 $(n=130)$ three years after the latest earthquake. Comparison of the 6 specific sites using the DSM 5 criteria, had shown marginal insignificant difference; but, using the DSM IV-TR diagnostic criteria, there was a strongly statistically significant difference of diagnostic rates between sites, $\left.X^{2}(5, \mathrm{n}=1081)=13.553, p=.019\right)$. Using the DSM IV-TR criteria rates climbed to a range of $33 \%$ and $27.5 \%$ in the two most remote Sumatran sites to $12.2 \%$ in Padang City, and from $22.8 \%$ in the most affected area of West Java to $22 \%$ in the other site.

Again, a preliminary test was performed using a logistic regression to determine if any of the various factors might be related to diagnostic rates. As in the earlier analysis gender appeared to be practically significant so a Chi Square was performed and revealed a significant difference between diagnosable rates by gender, $X^{2}(1, \mathrm{n}=1077)=5.785, p=.016$. Both genders had a higher incidence using the DSM IV-TR than using the DSM 5, and female participants continued to report a higher rate of PTSD (26.9\%, sd=.44) than did male participants $(20.6 \%, \mathrm{sd}=.40)$.

Because of such a wide difference between rates of PTSD diagnosis between the two American Psychiatric Association editions of the Diagnostic and Statistical Manual of Mental Disorders, with incidence being higher using the older edition, a paired sample t-test was performed to discover if the difference in overall incidence was statistically significant. The test revealed that the reduction in rates of diagnosable cases of PTSD in the sample population with the publication of the DSM 5 was indeed strongly significant $\left(\mathrm{t}_{1080}=13.452, \mathrm{p}=.001\right)$. The overall 
drop in diagnostic rate in the sample population was 3.14\%. A paired sample t-test was performed to determine if the drop of diagnostic rate was significant in the male sample population. The test revealed that the reduction in male PTSD rate between DSM IV-TR and DSM 5 was strongly significant $\left(\mathrm{t}_{466}=-2.763, \mathrm{p}=.006\right)$; the mean difference was $3.4 \%$. Another paired $\mathrm{t}$-test was performed, treating for female participants to determine if those PTSD rates were also statistically significant. The test revealed that the reduction in diagnostic rate was still convincingly significant ( $\left.\mathrm{t}_{609}=-2.258, \mathrm{p}=.024\right)$. The mean difference was $2.95 \%$.

\section{DISCUSSION}

Perhaps the most critical single discovery of this study lies in the overall rates of posttraumatic stress disorder several years after disaster. There is significant literature that indicates a consistent reduction in PTSD diagnostic rates over 5 years. Longitudinal studies of survivors consistently measure diagnostic rates at $2-3 \%$ of populations, 5 years after a major disaster. Yet survivors of the earthquakes and tsunamis in this study of disaster prone zones of Sumatra and West Java continued to present with extremely high incidence of diagnosable PTSD. Using the most conservative diagnostic criteria possible, the DSM 5 (American Psychiatric Association, 2013), the overall rate 3-6 years after major catastrophes was still $20.9 \%$. Considering the time variable between islands, West Java, which had experienced its last major earthquake 6 years before continued to present with a 19.63\% PTSD rate, while Sumatra, which had experienced its latest severe earthquake 3 years before, exhibited an overall PTSD rate of $22.52 \%$.

Factors that might contribute to this impeded decrease of symptoms must certainly include the unpredictability of life in these tectonically active territories, which have recently experienced a major event every three to five years. Add to that, dangerous and narrow roads with at times barely passable wooden bridges, occasionally dangerous living conditions, and dangerous animals, and some participants had reported as high as a dozen separate calamities that have befallen them. Since the research toward the revisions for PTSD diagnosis in the projected ICD 11 (Cloitre, et al., 2013) indicate that repeated traumatic experiences are related to dramatic increases in symptomology and more complex diagnostic patterns, it seems practical to assume that living in conditions of ongoing disaster threat would contribute to continued high PTSD rates.

However, other regions around the world experience frequent natural disasters and are, nevertheless, reported to show significant, subsiding PTSD symptoms over time. So, what might be unique in to this study is that, even after Indonesia created regions Disaster Management Bureaus, there has been little support of either the development of mental health counseling or for the inception of mental health disaster relief. Only the West Java Disaster Management Bureau has taken any steps toward collaboration to this end, and the effort has been minimal, contracting with a local university to provide community crisis intervention, not actual disaster mental health relief, and even then the interventions do not extend to disaster zones (F. Fridayanti, personal communication, November 24, 2015). The populations in the provinces that were studied had not received post-disaster psychological intervention.

This suggests that development of well-trained disaster mental health relief specialists and subsequent development of systems of care for disaster zones is an important and compelling necessity. Even though, universally, disaster psychological aftercare tends to be hodgepodge and ad hoc, it still appears to have significant influence on symptoms that lead to PTSD.

Secondarily, but perhaps as important for the therapeutic community and its clientele, were the findings from analysis of the significant drop in diagnosability of the study population 
when comparing the now obsolete DSM IV-TR and the recently published DSM 5. Analytic comparisons across the sample population and by factor constantly revealed strong statistical evidence of reduction in rates of diagnosis simply based on which criteria were used to reach diagnostic threshold. With p-values universally below .00, and with a $3.14 \%$ overall drop in diagnosed PTSD what appears to come into consideration is a significant reduction in sensitivity of the American Psychiatric Association's diagnostic criteria. Since there appear to be no APA studies that compare diagnostic rates between the two taxonomies, it is possible that this study's outcome is an anomaly, or it is easily as possible that either the APA did not do the research or, if they did, did not reveal the results.

Furthermore, at a time in US history when soldiers have returned from two major fields of combat many in need of trauma care, it is interesting that male diagnostic rates in the Indonesian study population dropped $3.4 \%$ from DSM IV-TR rates to those identified by the DSM 5, while female study participant rates dropped by only $2.95 \%$.

If further comparative research, conducted to replicate this study, elsewhere, revealed the same diagnostic incongruence, it would cast uncertainty and potential distrust onto the clinical sensitivity of the DSM 5 diagnostic schema. PTSD services are dependent on compassionate measurement of trauma to identify people in need of care. If said comparative research revealed a pattern of reliability between the two nosological schemas, it would not only show the results of this study to be potentially anomalies but would bolster suggestion of reliability of the new diagnostic schema.

The projected 2018 publication of the International Classification of Diseases, $11^{\text {th }}$ Revision will certainly provide the basis for another comparative taxonomy with the DSM 5 and might further challenge both the taxonomy of the DSM 5 as well as provide a more accurate diagnostic schema. Research toward this revision suggests that PTSD is more complex than present taxonomies suggest (Cloitre, et al., 2013). Further, the addition of this new nosological schema will provide rich ground for research.

Whatever is true, two outcomes of this study challenge the world, first to enhance, improve and develop both expertise in the field of disaster and trauma and secondly to develop more consistent and effective systems of care.

\section{References}

American Psychiatric Association. (2013). Diagnostic and statistical manual of mental disorders (5th ed.). Arlington, VA: American Psychiatric Publishing.

American Psychiatric Association. (2000). Diagnostic and statistical manual of mental disorders (4th ed., text revision). Washington, DC: Author.

Antara News (2009, October 5). Number of fatalities in west Sumatra quake now 1,115. Antara News . Retrieved from http://www.antara.co.id/en/news/1255472809/number-of fatalities-in-wsumatra quakenow-1-115

BBC News (2006, July 19). Indonesian death toll passes 500. Retrieved from http://news.bbc.co.uk/2/hi/asiapacific/5192716.stm.

Briere, J., \& Elliot, D. (2000). Prevalence, characteristics, and long-term sequelae of natural disaster exposure in the general population. Journal of Traumatic Stress, 13, 661-679.

Brown, M. L. (2006). Dams, doors, and divans: Staging a national narrative therapy in Chile, Argentina, and Spain. Dissertation Abstract International, 66(80-A).

Bryant, R. A. (2006). Recovery after the tsunami: Timeline for rehabilitation. Journal of Clinical Psychiatry, 67(2), 50-55. 
Chafee, A. P. (2012). A critical inquiry into the conceptual validity and clinical utility of borderline personality disorder given its interface with the bipolar spectrum and posttraumatic stress disorder. Dissertation Abstracts International: Section B: The Sciences and Engineering, 72(11-B), 2012. p. 7040.

Chen, C. C., Yeh, T. L., Yang, Y. K., Chen, S. J., Lee, I. H., Fu, L. S. Yeh, C. Y., Hsu, H.C., Tsai, W. L., Cheng, S. H., Chen, L. Y., \& Si, Y. C. (2001). Psychiatric morbidity and post-traumatic symptoms among survivors in the early stage following the 1999 earthquake in Taiwan. Psychiatry Research, 105(1-2), 13-22

Chung, M. C., Werrett, J., Farmer, S., Easthope, Y., \& Chung, C. (2000). Responses to traumatic stress among community residents exposed to a train collision. Stress and Health, 16(1), 17-25.

Cloitre, M., Garvert, D. W., Brewin, C. R., Bryant, R. A., \& Maercker, A (2013).

Evidence for proposed $I C D-11$ and Complex PTSD: A latent profile analysis. European Journal of Psychotraumatology, 4, 20706-20717.

Dewaraja, R., \& Kawamura, N. (2006). Trauma intensity and posttraumatic stress: Implications of the tsunami experience in Sri Lanka for the management of future disasters. International Congress Series, 1287, 69-73.

Downs, L. L., \& Othman, S. A. (2015). The incidence of posttraumatic stress symptoms among adults and children in the Phang Nga region of Thailand. VISTAS, Retrieved from https://www.counseling.org/knowledgecenter/vistas/by subject2/vistas-crisis/docs/default-source/vistas/the-incidence-of-posttraumatic stresssymptoms-among-adults-and-children-in-the-phang-nga-region-of-thailand

Downs. L. L., Rahmadian, A. A., Masril, Ardimen, Hendriani, S., Othman, S. A., Kim,

D., \& Koay, T. L. (2015). A reliability study of the Downs Postraumatic Stress Scale: A refined instrument for measuring the effects of human catastrophes. Journal of Education Research and Behavioral Sciences Vol. 4(2), 6774.

Du, Y. B., Lee, C. T., Christina, D, \& Belfer, M. L., Betencourt, T. S., O’Rourke, E. J, \& Palfry, J. S. (2012). The living environment and children's fears following the Indonesian tsunami. Disasters, 36(3), 495-513.

Ehntholt, K. A., \& Yule, W. (2006). Practitioner review: Assessment ands treatment of refugee children and adolescents who have experienced war-related trauma. Journal of Child Psychology and Psychiatry, 47(12), 11971210.

Fairbrother, N., \& Rachman, S. (2006). PTSD in victims of sexual assault: Test of a major component of the EhlersClark theory. Journal of Behavioral Therapy and Experimental Psychiatry, 37, 74-93.

Flamez, B., King, J. H., \& Francis, J. (2015). Conceptualizing DSM-5 Disorders in Children and Adolescents. Diagnosing and Treating Children and Adolescents: A Guide for Mental Health Professionals, 1.

Frueh, B. C., Elhai, J. D., \& Acierno, R. (2010). The future of posttraumatic stress disorder in the DSM. Psychological Injury and the Law, 3(4), 260-270.

Ghazali, S. R., Yaman, K., \& Ahmad, M. (2012). DSM-IV PTSD symptoms, socio-demographic characteristics and lifetime traumas among adults exposed to 2004

tsunami disaster in Malaysia. European Psychiatry, Supplement, 27, 1.

Ghodse, H., \& Galea, S. (2006). Tsunami: understanding mental health consequences and the unprecedented response. International Review of Psychiatry, 18(3), 289-297.

Ito, H., Setoya, Y, \& Suzuki, Y. (2012). Lessons learned in developing community mental health care in East and South East Asia. World Psychiatry, 11(3), 166-190.

Iverson, K. M., Gradus, J. L., Resick, P. A., Suvak, M. K., Smith, K. F., \& Monson, C.M. (2011). Cognitive-behavioral therapy for PTSD and depression symptoms reduces risk for future intimate partner violence among interpersonal trauma survivors. Journal of Consulting and Clinical Psychology, 79(2), 193-202.

Iwadare, Y., Usami, M., Suzuki, Y., Ushijima, H., Tanaka, T., Watanabe, K., Kodaira, M., \& Sato, K. (2014). Posttraumatic symptoms in elementary and junior high school children after the 2011 Japan earthquake and tsunami: Symptom severity and recovery vary by age and sex. The Journal of Pediatrics, 164(4), 917-921.

John, P.B., Russell, S., \& Russell, P. S. (2007). The prevalence of posttraumatic stress disorder among children and adolescents affected by tsunami disaster in Tamil Nadu. Disaster Management Response, 5(1), 3-7. 
Kar, N., \& Bastia, B. K. (2006). Post-traumatic stress disorder, depression and generalised anxiety disorder in adolescents after a natural disaster: a study of comorbidity. Clinical Practice and Epidemiology in Mental Health, 2(1), 17.

Keane, T. M., Wolfe, J., \& Taylor, K. L. (1987). Post-traumatic stress disorder: Evidence for diagnostic validity and methods of psychological assessment. Journal of clinical psychology, 43(1), 32-43.

Kokai, M., Fujii, S., Shinfuku, N., \& Edwards, G. (2004). Natural disaster and mental health in Asia. Psychiatry and Clinical Neurosciences, 58, 110-116

Kompas.com. (2009, October 15). 1117 orang meninggal akibat gempa Padang. Retrieved from http//www.google.com/search?q=gempa+padang+2009\&i=utf8\&oe=utf8aq=t\&rls= orgmozilla:en US:official\&client=firefoxa \&channel=np\&source=hp\#channelnp.

Kumar, M. S., Murhekar, M. V., Hutin, Y., Subramanian, T., Ramachandran, V., \& Gupte, M. D. (2007). Prevalence of posttraumatic stress disorder in a coastal fishing village in Tamil Nadu, India, after the December 2004 tsunami. American Journal of Public Health, 97(1), 99-101.

Kvavilashvili, L. (2014). Solving the mystery of intrusive flashbacks in posttraumatic stress disorder: Comment on Brewin (2014). Psychological Bulletin, 140(1), 98-104.

Kuwabara, H., Shioiri, T., Toyabe, S., Tsuyoshi, K., Masataka, K., Ito-Sawamura, M., Akazawa, K., \& Someya, T. (2008). Factors impacting on psychological distress and recovery after the 2004 Niigata-Chuetsu earthquake, Japan: Community based study. Psychiatry Clinical Neuroscience, 62(5), 503-507.

Leitmann, J. (2007). Cities and calamities: Learning from post-disaster response in Indonesia. Journal of Urban Health, 84(1), 144-153.

Norris, F. H., Friedman, M. J., Watson, P. J., Byrne, C. M., Diaz, E., \& Kaniasty, K. (2002). 60,000 disaster victims speak: Part I. An empirical review of the empirical literature, 1981-2001. Psychiatry, 65(3), 207-239.

Ozer, E. J., Best, S. R., Lipsey, T. L., \& Weiss, D. S. (2008). Predictors of posttraumatic stress disorder and symptoms in adults: A meta-analysis. Psychological Trauma: Theory Research, Practice and Policy, S(1), 3-36.

Panyayong, B., \& Pengjuntr, W. (2006). Mental health and psychosocial aspects of disaster preparedness in Thailand. International Review of Psychiatry, 18(6), 607614.

Piyasil, V., Ketumarn, P., Prubrukarn. R., Ularntinon, S., Sitdhiraksa, N., Pithayaratsathien, N., Pariwatcharakul, P., Lerthattaslip, T., Chinajitphant, N., Liamwanich, K., Wadchareeudomkarn, N., Sookatup, J., Wanlieng, T., Yongpitayapong, C., Paveenchana, P., Tasri, L, Chaiyakun, P., \& Sanguanpanich, N. (2011). Post-traumatic stress disorder in children after the tsunami disaster in Thailand: A 5-year follow-up. Journal of the Medical Association of Thailand, 94 (Suppl 3), 138-144.

Piyavhatkul, N., Pairojkul, S., \& Suphakunpinyo, C. (2008). Psychiatric disorders in tsunami-affected children in Ranong province, Thailand. Medical Principles \& Practice, 17(4), 290-295.

Pramono, A (2014). Monte Carlo Analysis for Earthquake Mitigation at Refinery Complex. Pertamina Merdeka Timur, 1A, Jakarta: Indonesia.

Pyari, T. T., Kutty, R. V., \& Sarma, P. S. (2012). Risk factors of post-traumatic stress disorder in tsunami survivors of Kanyakumari District, Tamil Nadu, India. Indian Journal of Psychiatry, 54(1), 48.

Rao, K. (2006) 'Psychosocial support in disaster-affected communities'. International Review of Psychiatry.18(6), 501-505

Robertson, M., Rushton, P. J., Bartrum, D., \& Ray, R. (2004). Group-based interpersonal psychotherapy for posttraumatic stress disorder: Theoretic and clinical aspects. International Journal of Group Psychotherapy, 54(2), 145-175.

Rose, G. M., Spitzer, R. L., \& McHugh, P. R. (2008). Problems with the posttraumatic stress disorder diagnosis and its future in DSM-V. British Journal of Psyciatry, 192(5), 395.

Satapathy, S., \& Walla, A. (2006). Intervening with the process of recovery from a traumatic life event: Case study of a child victim of a school fire disaster in India. Australian E-Journal for the Advancement of Mental Health, 5, 1-7.

Satapathy, S., \& Subhasis, B. (2009). Disaster psychosocial and mental health support in South and South-East Asian countries: A synthesis. Journal of South Asia Disaster Studies, 2(1), 21-45.

Schnurr, P. P. (2010). PTSD 30 years on. Journal of Traumatic Stress, Editorial, 23(1),1-2. 
See, C. M. (2005, December). Observations on the counseling of tsunami survivors in Malaysia. Proceedings of the $11^{\text {th }}$ International Counseling Conference, Bangkok, Thailand, 75-82.

Soysa, C. K. (2013). Interventions to promote reintegration of traumatized youth conscripted as child soldiers. Journal of Aggression: Maltreatment \& Trauma, 22(8), 896-915.

Stratton, K. J., Aggen, S. H., Richardson, L. K., Tran, T. L., Nguyen, T. T., Berenz, E. C., Trung, L. T., Tuan, T., Buoi, L. T., Ha, T. T., Thach, T. D., \& Amstadter, A. B. (2014) . "Using the SRQ 20 factor structure to examine changes in mental distress following typhoon exposure." Psychological Assessment 26(2), 528-536.

Suwarni, Y.T. (2011, November 30). West Java Province threatened by population explosion. The Jakarta Post, Bandung, West Java. Retrieved from http://www.thejakartapost.com/news/2011/11/30/westjava- provincethreatened population-explosion.html

Tang, C. S. (2007). Trajectory of traumatic stress symptoms in the aftermath of extreme natural disaster: a study of adult Thai survivors of the 2004 Southeast Asian earthquake and tsunami. Journal of Nervous \& Mental Disease, 195(1), 54-59.

Thavichachart, S., Thangwongchai, S., Worakul, P., Kanchantawan, B., Suppapitiporn, S., Sukoltapirom na Pattalung, A., Chareonsook, O. (2009). Posttraumatic stress disorder of the tsunami survivors in Thailand. Journal of the Medical Association of Thailand, 92(3), 420-429.

Thienkrua, W., Cardozo, B. L., Chakkraband, M. L., Guadamuz, T. E., Pengjuntr, W., Tantipiwatanaskul, P. Sakornsatian, S., Ekassawin, S., Panyayong, B., Varangrat, A., Tappero, J. W., Schreiber, M., \& van Griensven, F. (2006). Symptoms of

Posttraumatic stress disorder and depression among children in tsunami-affected areas in southern Thailand. Journal of the American Medical Association. 296(5), 549-559.

Udomratn, P. (2008). Mental health and the psychosocial consequences of natural disaster in Asia. International Review of Psychiatry, 20(5), 441-444.

Ulartinon, S., Piyasil, V., Ketumarn, P., Sitdhiraksa, N., Pityaratstian, N., Lerthattasilp, T. Bunpromma, W., Booranasuksaiul, T. Reuangsorn, S., Teeranukul, S., \& Pimratana, W. (2008). Assessment of psychopathological consequences in children at 3 years after tsunami disaster. Journal of the Medical Association of Thailand. 91(Supplement 3), 69-75.

US Department of Veterans Affairs, National Center for PTSD (2013). Traumatic Effects of Specific Types of Disasters. Retrieved August 7, 2014 from http://www.ptsd.va.gov/professional/trauma/disasterterrorism/traumaticeffects-disasters.asp van Griensven, F., Chakkraband, M. L., Thienkrua, W., Pengjuntr, W., Lopes Cardoaz,

B., Tantipiwatanaskul, P., Mock, P. A., Ekassawin, S., Varangrat, A., Gotway, C., Sabin, M., \& Tappero, J. W. (2006). Mental health problems among adults in tsunami-affected areas in southern Thailand. Journal of the American Medical Association, 296(5), 537-548.

Varley, C. K. (2015). Overview of DSM Changes. Seattle, WA: Seattle Children's Hospital Research Foundation.

Vijayakumar, L., Kannan, G. K., \& Daniel, S. J. (2006). Mental health status in children exposed to tsunami. International Review of Psychiatry. 18(6). pp. 507-13.

Warta KB dan KS BKKBN Prov. Sumatera Barat No. 02 Tahun 2011. Jumlah penduduk Sumatera Barat terus bertambah. Retrieved from http://sumbar.bkkbn.go.id/infoprogram/Documents/479190897.

Williams, B., \& Audet, L. R. (2015). DSM-V changes in the diagnosis of Autism' Spectrum Disorders \& Implications for the Speech-Language Pathologist. Hearsay, 45. World Health Organization (2010). International Statistical Classification of Diseases and Related Health Problems, Tenth Revision (ICD-10). Geneva, Switzerland: United Nations World Health Organization. 